\title{
LA DELINCUENCIA FEMENINA: UNA REVISIÓN TEÓRICA
}

\author{
Antonio Jesús Yugueros García \\ Doctor por la Universidad Pablo de Olavide \\ antyugue@hotmail.com
}

\section{INTRODUCCIÓN}

En todas las disciplinas del saber, en general, las mujeres han sido omitidas de los estudios realizados a lo largo de la historia, entre otras razones porque no se las ha dejado ocupar espacios en la esfera pública. Éste es el caso, igualmente, de la ciencia criminológica, donde podemos observar la inexistencia de estudios sobre la delincuencia femenina hasta la segunda mitad del siglo XIX, aunque, sin embargo, el comportamiento delictivo femenino ha existido en todos los periodos históricos, eso sí, en mucha menor medida que en la conducta ilícita masculina, y ésta es precisamente la excusa que se ha esgrimido, ante la fatalidad de carecer de datos precisos sobre la temática. Frente a ello, lo que se realizaba era la valoración de los datos de la delincuencia conjuntamente, es decir, no segregándola por sexos, medida, como se sabe, poco acertada desde el punto de vista epistemológico, porque las motivaciones para delinquir entre hombres y mujeres difieren, aunque haya algún acercamiento desde el ámbito social. Otras veces estas cifras componían un anexo de las estadísticas oficiales de la delincuencia total (De la Cuesta, 1992).

\section{ANÁLISIS DE LAS PERSONAS RECLUSAS EN LA ACTUALIDAD}

Actualmente, si examinamos las estadísticas aportadas por el Ministerio del Interior (Anuario 2010), se aprecia notoriamente que hay más hombres cumpliendo condena en las cárceles españolas que mujeres, de tal manera que la población reclusa a finales del año 2010, en el total nacional, era de 73.929 personas; 68.141 hombres y 5.788 mujeres (en estos datos está incluida la población penitenciaria de la Comunidad Autónoma de Catalunya, que tiene competencia en la gestión de los centros penitenciarios de su demarcación): 


\begin{tabular}{|c|c|c|c|}
\hline Año & Hombres & Mujeres & Total \\
\hline 2010 & 68.141 & 5.788 & 73.929 \\
\hline
\end{tabular}

Con lo que se puede colegir de estos datos que 9 de cada 10 personas reclusas son varones, es decir un 92,17 por 100 , frente al 7,83 por 100 que corresponde a las mujeres en la misma situación.

En el siguiente cuadro se desglosa la edad de las personas que cumplen condena (descartando a las que se encuentran en situación preventiva):

\begin{tabular}{|l|r|r|r|}
\hline \multicolumn{1}{|c|}{ Edades penados/as } & Hombres & Mujeres & Total \\
\hline 18 a 20 años & 651 & 24 & 675 \\
\hline 21 a 25 años & 6.623 & 467 & 7.090 \\
\hline 26 a 30 años & 11.206 & 933 & 12.139 \\
\hline 31 a 40 años & 19.214 & $\mathbf{1 . 5 2 0}$ & 20.734 \\
\hline 41 a 60 años & 15.711 & $\mathbf{1 . 4 0 9}$ & 17.120 \\
\hline Más de 60 años & 1.388 & 105 & 1.493 \\
\hline
\end{tabular}

Y en el siguiente se ofrece una tipología delictiva de la población reclusa penada en aplicación del actual Código Penal de 1995:

\begin{tabular}{|l|r|r|r|}
\hline \multicolumn{1}{|c|}{ Delitos } & Hombres & Mujeres & \multicolumn{1}{c|}{ Total } \\
\hline Homicidio y sus formas & 2.963 & 194 & 3.157 \\
\hline Lesiones & 3.112 & 156 & 3.268 \\
\hline Contra la libertad & 593 & 33 & 626 \\
\hline Contra la libertad sexual & 3.644 & 55 & 3.699 \\
\hline Contra el honor & 19 & 0 & 19 \\
\hline Contra las relaciones familiares & 1.474 & 21 & 1.495 \\
\hline Contra el patrimonio y orden socioeconómico & 21.426 & $\mathbf{1 . 3 5 3}$ & 22.779 \\
\hline Contra la salud pública & 14.025 & $\mathbf{2 . 2 0 2}$ & 16.227 \\
\hline Contra la seguridad tráfico & 1.203 & 21 & 1.224 \\
\hline Falsedades & 670 & 73 & 743 \\
\hline Contra la Administración Pública & 67 & 6 & 73 \\
\hline Contra la Administración de Justicia & 1.247 & 59 & 1.306 \\
\hline Contra el orden público & 1.593 & 84 & 1.677 \\
\hline Resto de delitos & 1.589 & 93 & 1.682 \\
\hline
\end{tabular}




\begin{tabular}{|l|r|r|r|}
\hline \multicolumn{1}{|c|}{ Delitos } & Hombres & Mujeres & \multicolumn{1}{c|}{ Total } \\
\hline Faltas & 133 & 26 & 159 \\
\hline No consta delito & 270 & 37 & 307 \\
\hline TOTAL & 54.028 & 4.413 & 58.441 \\
\hline
\end{tabular}

En este cuadro se observa que cumplen condena por delitos contra el patrimonio y orden socioeconómico un total de 21.426 hombres $(39,7$ por 100) y por delito contra la salud pública 14.025 internos (26 por 100), ambos delitos representan en varones el 65,7 por 100 del total de delitos. En cuanto a las mujeres, cumplen condena por delito contra la salud pública un 49,9 por 100 y por delitos contra el patrimonio y orden socioeconómico en un 30,7 por 100 , ambos delitos representan en mujeres un 80,6 por 100 del total de delitos.

Como se puede apreciar, la gran mayoría de mujeres que cumplen condena en nuestro país lo hace por delitos relacionados con las drogas, directa o indirectamente, y por delitos contra el patrimonio, que en su gran mayoría están motivados por el consumo de drogas. En el caso de los hombres, la mayoría de delitos también está relacionada con las drogas, pero la tipología delictiva resultante es bastante diferente, ya que en los hombres el delito mayoritario es contra el patrimonio y en segundo término contra la salud pública, y el resto de delitos representa una quinta parte del conjunto, que en el caso de las mujeres son delitos casi inexistentes (ALMEDA, 2003).

\section{ALGUNAS TEORÍAS CLÁSICAS SOBRE LA DELINCUENCIA FEMENINA}

No será hasta la segunda mitad del siglo XIX cuando comienzan a elaborarse estudios sobre la delincuencia femenina. Inicialmente, las teorías biologicistas, con autores como Lombroso y Ferrero (1895), consideraban a la mujer como inferior al hombre en el marco evolutivo y, por esta razón, con menos capacidad de delinquir, debido a lo cual presentaría una tasa inferior de delitos. También le atribuían una mayor crueldad, al identificarla con lo primitivo, infiriéndole una mayor comisión de delitos de sangre, aseverando, por otra parte, que su mejor capacidad de adaptación la llevaría a combinar las peores características de la mujer —astucia, rencor y falsedadcon aquellas otras de la criminalidad masculina, disponiendo, además, de mayor habilidad en su trato con la justicia (CANTERAS Murillo, 1990). Si se 
observan las estadísticas actuales, se puede apreciar el bajo índice de delitos de homicidios y lesiones perpetrados por las mujeres, y este hecho es una constante a lo largo de la historia, con lo cual las aseveraciones de estos autores no se sostienen con los argumentos falaces que esgrimen.

Otro autor de esta misma línea de pensamiento, Gray (LEGANES y ORTOLA, 1999), afirmaba que la mayor agresividad del hombre respecto de la mujer es debido a la mayor presencia en aquél de hormonas andrógenas, por ello en el comportamiento criminal femenino hay menor agresividad. Actualmente existe consenso en afirmar que la agresividad es un componente biológico necesario para la supervivencia del ser humano, sin embargo, la violencia es modulada por el componente cultural, entendiendo ésta como toda acción o inacción que produce daño físico o no a otro ser humano, sin que haya beneficio para la eficacia biológica propia (SANMARTín, 2000)

Pero donde más hincapié se ha realizado a lo largo de la historia ha sido en el comportamiento durante las fases de desarrollo sexual y durante la crisis catamenial (B. AzNAR, 1968). Este mito, porque no puede considerarse de otra manera, permanece activo en el ideario colectivo; pero no deja de ser un reduccionismo de la realidad criminológica, ya que en el componente delictivo coexisten variables diferentes, interrelacionadas entre sí, no pudiéndose atribuir la delincuencia, ya sea femenina o masculina, a una sola causa.

Otros autores imputaban la delincuencia femenina a partir de las diferencias genéticas observadas entre las mujeres delincuentes y las que no lo son (ELLIS, 1982). Freud, desde su explicación psicoanalítica, afirmó que la mujer delincuente es un ser anormal, ya que la agresividad es propia del hombre. En definitiva, todos estos autores sostenían que la delincuencia femenina se debía a particularidades biológicas del sexo femenino, realizando comparaciones no tanto con la delincuencia masculina como con las mujeres no delincuentes (De la Cuesta, 1992).

Posteriormente llegarían las teorías sociales (J. G. WeIs, 1982), las cuales fijan su atención en la importancia de la socialización diferencial entre hombres y mujeres a la hora de desempeñar sus roles respectivos, rechazando los determinismos biológicos de carácter individual antes descritos. De esta forma, los funcionalistas de la teoría del rol aducían que, como consecuencia de la liberación de la mujer, ésta rompería con su rol sexual tradicional, aproximando progresivamente su delincuencia al perfil masculino, es decir, que la liberación de la mujer derivaría en unas pautas de comportamiento similares a las del hombre, incluso en el plano delictivo. De igual modo era el pensamiento de la teoría de la igualdad de oportu- 
nidades, que postulaba que la integración de la mujer en la esfera pública debería traer consigo una elevación de sus tasas de criminalidad hasta llegar a equiparase a las del varón. Ante esto hay que decir que, aunque efectivamente desde los años sesenta del siglo pasado el número de mujeres detenidas ha aumentado, el índice de penadas en la actualidad es del 7,83 por 100 del total de la población reclusa, con lo cual los pronósticos de Weis y sus seguidores no han tenido el acierto que esperaban.

Dentro de las orientaciones críticas tenemos el punto de vista de la teoría del control social (T. MiralLes, 1983) y la teoría de la ley de la dependencia económica. La primera aduce que el control, tanto en el plano micro como macro social, conforma progresivamente un concepto de mujer socialmente funcional, creando el papel que a ésta se le ha asignado en la sociedad, y la segunda argumenta la mayor o menor dureza o benignidad de aplicación de las penas a la mujer.

\section{POBLACIÓN RECLUSA EXTRANJERA}

Con respecto a la población reclusa extranjera, se observa, al igual que en la población reclusa española, un porcentaje muy bajo de mujeres en esta situación.

\begin{tabular}{|l|c|c|}
\hline \multicolumn{1}{|c|}{ Género } & Total & Porcentaje \\
\hline Hombres & 24.020 & 91,28 \\
\hline Mujeres & 2.295 & 8,72 \\
\hline TotaL & 26.315 & 100,00 \\
\hline
\end{tabular}

Fuente: Anuario estadístico del Ministerio del Interior, 2012.

\section{POSIBLES CAUSAS DE LA DELINCUENCIA FEMENINA}

Muy sintéticamente, las causas por las cuales las mujeres delinquen son debidas mayoritariamente a la pobreza, exclusión social, falta de instrucción educativa y otras circunstancias socioculturales. Este es precisamente el perfil que presenta la mayoría de las mujeres que cumplen condena en las cárceles españolas. Respecto a los posibles motivos por los que comenten menos delitos que los hombres existen varias hipótesis, entre ellas la teoría del control social, su menor fortaleza física, etc. Es un campo, creo, abierto para profundizar en su estudio. 


\section{CONCLUSIONES}

Como se ha puesto de manifiesto, las teorías que daban explicación a las causas de la delincuencia femenina tenían un marcado cariz androcéntrico, debido a lo cual en la actualidad no se sostienen. Los postulados de los diversos autores se ceñían a características biológicas y médicas, no teniendo en cuenta el entorno sociocultural de las mujeres delincuentes. La delincuencia femenina no se puede ceñir a un solo ámbito de estudio, es multidisciplinar.

Hay un rasgo, sin duda, que caracteriza a la población reclusa, en general, que cumple penas privativas de libertad en las prisiones españolas: la pobreza y exclusión social. En las mujeres se agrava esta situación porque, además, suelen constituir familias monoparentales y son responsables del cuidado de sus hijos e hijas, sin embargo, el índice de delitos cometidos por las mujeres es muy inferior al de los hombres, por lo que no se puede considerar como única causa de la delincuencia femenina estas variables. Para terminar, siguiendo a Elisabet Almeda, el objetivo final de las cárceles de mujeres se dirige a su corrección, no solamente porque hayan vulnerado la ley, sino porque se han desviado socialmente del rol social que se les ha asignado.

\section{BIBLIOGRAFÍA}

Almeda, E., Mujeres encarceladas, Madrid, Ariel, 2003.

Anuario Estadístico del Ministerio del Interior, 2010.

Aznar, B., Notas para un estudio sobre biología criminal de la mujer (la delincuencia catamenial), Madrid, Escuela de Medicina Legal, 1968.

Canteras, A., Delincuencia femenina en España. Un análisis sociológico, Madrid, Centro de Publicaciones del Ministerio de Justicia, 1990.

De la Cuesta, P. M., «Perfiles criminológicos de la delincuencia femenina», Revista de Derecho Penal y Criminológico, núm. 2, 1992.

Leganés, S., y Ortolá, E., Criminología. Parte Especial, Valencia, Tirant lo Blanch, 1999.

Ley Orgánica 10/1995, de 23 de noviembre, del Código Penal.

Lombroso, C., y Ferrero, G., The Female Offender, London, Fisher Unwin, 1895.

Miralles, T.; Bergalli, R., y Bustos, J., El pensamiento criminológico, t. II, Estado y control, Barcelona, Península, 1983, pp. 37 y ss.

San Martín, J., La violencia y sus claves, Madrid, Ariel, 2004.

WeIs, J. G., «The Invention of the New Female Criminal», en L. D. SAvitz y N. Johnston, Comtemporary Criminology, New York, John Wiley, 1982. 